\title{
RESEÑA: MARISA MADIERI. ESCRITORAS DEL ÉXODO Y DEL EXILIO. PEDRO LUIS LADRÓN DE GUEVARA, Ma BELÉN HERNÁNDEZ GONZÁLEZ, ZOSI ZOGRAFIDOU (EDS.) ${ }^{1}$
}

\author{
Fuensanta María Piqueras Casado
}

\begin{abstract}
Pedro Luis Ladrón de Guevara, Mª Belén Hernández González, Zosi Zografidou (eds.), Marisa Madieri. Escritoras del éxodo y del exilio. Murcia: Editum, 2015. ISBN: 978-84-16551-22-4
\end{abstract}

Marisa Madieri es una escritora italiana de trayectoria insólita en el ámbito de las letras y la vida. Nacida en la ciudad de Fiume en 1938, sufrió en carne propia la persecución y el exilio cuando Tito anexionó este territorio a la antigua Yugoslavia, en 1949. Junto a su familia y muchos otros desterrados, Madieri se instaló en la ciudad fronteriza de Trieste, en un almacén de grano provisionalmente destinado a los refugiados, llamado Silos. Sin embargo, los años pasaron y la condición de refugiados se prolongó para los suyos durante casi una década. De las condiciones de vida de estos prófugos, italianos pero extranjeros en Italia, versa principalmente la obra narrativa de Marisa Madieri, analizada junto a otras escritoras exiliadas en este libro, publicado recientemente por Editum en la Universidad de Murcia.

El volumen consta de 370 páginas divididas en dos partes, que a continuación se reseñarán, y está prologado por Claudio Magris, cónyuge de Marisa y albacea de la autora, fallecida en 1996. Magris escribe al inicio:

\footnotetext{
${ }^{1}$ Fecha de recepción: 30/08/2015.

Fecha de aceptación: 07/09/2015. ${ }^{2}$ Profesora Asociada, Departamento de Filología Francesa, Románica, Italiana y Árabe, Universidad de Murcia; $₫$ fuensantamaria.piqueras@um.es.
} 
He visto nacer los libros de Marisa, que contienen mi vida más que los que he escrito yo. [...] Creo que conozco a fondo su obra; he escrito sobre ella muchas veces, y ampliamente. [...] Pero esta vez, con este volumen, el viaje es para mí una travesía grande y reveladora. Leyendo estos ensayos me adentro en un mundo que a menudo es nuevo incluso para mí; descubro dimensiones, temas, músicas y ritmos, detalles por los que había pasado cerca con pasión pero a veces sin captar su claridad. (9)

Claudio Magris siempre ha agradecido el interés precoz de los lectores españoles por la obra de Marisa Madieri; aunque la autora con el paso de los años ya no es vista sólo como compañera del gran escritor triestino, pues por sí misma se ha consolidado como un valor de las letras contemporáneas, tanto en italiano como en otras literaturas a las que ha sido traducida (francés, inglés, alemán, húngaro, esloveno, griego). Los ensayos recopilados aquí son una selección de los presentados en un congreso internacional homenaje a Marisa Madieri, presidido por Pedro Luis Ladrón de Guevara en la Universidad de Murcia en 2015 con la presencia del propio Magris, y dedicado también a otras narradoras de exilios y éxodos de distintos países o épocas. Junto a los trece ensayos sobre Madieri, se leen estudios de otras trece escritoras tan arrinconadas por la historia de la literatura como merecedoras de sobresalir en ella.

Siguiendo el índice del libro, en la primera parte, se encuentran agrupados los ensayos sobre la obra y la figura de Marisa Madieri. Repasando las contribuciones brevemente, destaca la de Elvio Guagnini, catedrático de literatura de la Universidad de Trieste, amén de amigo personal de la autora, a la cual dedica una profunda reflexión titulada Piccole gocce dell'oceano vissuto; páginas que evocan la particular capacidad de condensar experiencias de la memoria en momentos armónicos del presente: Marisa, para Guagnini, narra una gran página de la historia italiana, pero lo hace de forma privada, esencial, destacando la belleza de lo vivido y la aspiración por una verdad esencial. Mercedes Montmany, crítica literaria, destaca en Marisa Madieri: mi Fiume, el ambiente de la infancia de la escritora y el impacto de la tragedia de la guerra con la inseguridad por el territorio y la desaparición de personajes queridos. M. Belén Hernández, de la Universidad de Murcia, en Notas sobre la idea de novela de Marisa Madieri realiza un análisis sobre la poética narrativa de Marisa, relacionándola por su esencialidad y 
concepción espacio-temporal con sus autores predilectos: el mar de Ibsen, Michelstaedter, Stuparich y el propio Magris. Paulino Matas, catedrático de la Universidad de Salamanca, recientemente desaparecido, en una de sus últimas intervenciones, nos deja un texto titulado Verde acqua de Marisa Madieri: la construcción narrativa de un dramático éxodo, donde describe con realismo el coro de personajes femeninos de Verde Acqua y su capacidad para escenificar la tragedia de la fuga. Mercedes Arriaga, catedrática de la Universidad de Sevilla, en Senza luoghi e senza alivi. La scrittura di Marisa Madieri describe los escenarios narrativos de Madieri, denominados no lugares, pues se encuentran solamente en el espacio interior de la autora y paralelamente se dan en un tiempo que se dilata o se contrae en dependencia de las sensaciones. En el capítulo seis, titulado: Marisa Madieri: las resplandecientes palabras de una escritora en la sombra, Pérette-Cécile Buffaria polemiza sobre la intromisión de Magris en la obra de Madieri, cuya consecuencia ha sido la injusta etiqueta de escritora en la sombra, mientras ella posee luz propia, como el tiempo ha demostrado. Encarna Esteban Bernabé, profesora de la Universidad de Murcia, presenta propuestas para utilizar el relato La Radura en la clase de italiano para niveles desde A1 a B2, en el trabajo titulado: La Radura de Marisa Madieri. Un texto literario en el aula de ILS. María Reyes Ferrer, también de la Universidad de Murcia, analiza un insólito ensayo de Madieri, en realidad su tesina de licenciatura sobre la obra de Lehmann, en el capítulo titulado: Marisa Madieri y su estudio literario: un acercamiento a la obra de Rosamond Lehamann. Julia Benavent, de la Universidad de Valencia, compara dos autoras de distinta índole, la escritora italiana y una de sus críticas españolas (que también vivió el exilio), en el ensayo Palabras del exilio: Marisa Madieri y Teresa Gracia. Siguen algunos capítulos sobre la fortuna de la obra de Madieri en distintas culturas: Pedro Luis Ladrón de Guevara en Presenza di Marisa Madieri in Spagna, describe con detalle las intervenciones críticas sobre la autora por orden cronológico, mostrando la creciente aceptación de su obra en nuestro país. Leonor Sáez Méndez en el capítulo La acogida de Verde Acqua-Wassergrün en lengua alemana, repasa la recepción de la autora en dicha lengua y el interés suscitado por su obra en el ámbito germánico, tan cercano a la familia Magris. Andrea Ladrón de Guevara Quintela muestra el impacto de la obra de Madieri en francés y compara variantes en distintas traducciones, en Marisa Madieri en Francia: sus traducciones. Concluyendo 
esta parte, Zosi Zografidou, traductora al griego de Madieri y profesora de la Universidad de Salónica, describe los estilemas más originales de los relatos de Marisa y el momento de su presentación al público griego a través de sus traducciones.

En el meridiano del volumen los editores han incluido un interesantísimo apéndice con algunos materiales que constituyen una primicia incluso para el lector italiano y serán imprescindibles para los futuros estudiosos de Madieri. Se trata de unos apuntes redactados por la autora con motivo de entrevistas de radio y otras notas autógrafas sobre su propia obra, presentados en versión bilingüe italiano-español. Asimismo el apéndice comprende una biografía realizada por Ladrón de Guevara y una bibliografía actualizada, elaborada por Zografidou, donde se refieren también las distintas traducciones, declaraciones de prensa de la autora y una completa bibliografía crítica.

La segunda parte del libro, dedicado a éxodos y exilios de otras escritoras, reúne otros tantos capítulos ordenados según la cronología de las autoras. En el capítulo 14, Mercedes Tormo-Ortiz desarrolla el éxodo bíblico a partir a de la Peregrinatio Egeriae; Egeria a finales del S. IV escribía un tratado sobre el éxodo del pueblo de Israel, se ha estudiado como un relato de viajes, que junto a información arqueológica y paleográfica, aporta rasgos de la autora sorprendentes para la época. Antonia Viñez Sánchez presenta Contextualización y exilios de las Trobairitz, trovadoras occitanas del S. XIII cuyas vidas proporcionan datos sobre sus composiciones poéticas y formación. Milagro Martín Clavijo en el capítulo titulado El doble exilio de las patriotas jacobinas, describe la situación de las mujeres ilustradas durante el Trienio jacobino en Italia y aporta datos sobre las condiciones del exilio de algunas de las figuras femeninas más destacadas del momento. Eva M. Moreno Lago relata la fundación del Lyceum Club de Madrid y su auge con más de 500 asociadas en 1929; tras la guerra muchas de las socias tuvieron que exiliarse y relataron dicha experiencia en sus escritos autobiográficos. Sobre esta misma época y una de sus figuras más emblemáticas trata el capítulo 18, de M. Teresa Arias Bautista: A flor de piel, sentimientos en el exilio. El caso de Victoria Kent. Anna Mellado García presenta María Teresa León, embajadora de la República española en su exilio italiano; el texto recrea el ambiente intelectual de la Roma de las décadas 50 y 60, así como la actitud ideológica y luchadora de León como referente para otros escritores. 
Francesco Ghera aporta un texto sobre Maria Giacobbe, autora sarda instalada en Dinamarca, cuya obra está dedicada a la memoria de sus raíces en busca de una identidad perdida. En el capítulo siguiente (21), Victoriano Peña propone un análisis de la vida y la obra de Marina Jarre, nacida en Letonia de madre italiana y padre judío; en su obra autobiográfica I padri lontani la autora relata la herida del exilio y la fragmentación de su propia identidad. Abdullah al-Amar es autor del Estudio estilístico y analítico del exilio en la poesía de Dunia Mikhail; se trata de una poetisa iraquí, nacida en 1965 y huída a EE.UU en 1996 tras años de amenazas. Juan de Dios Torralbo presenta en el capítulo siguiente la obra poética de Elizabeth Bishop y en concreto analiza el poema The Map, interpretándolo como el símbolo del exilio interior. Juana Castaño Ruiz en el ensayo titulado: Éxodo y exilios. Inmigrantes literarios de Ana Lydia Vega, Edwidge Danticat, Julia Álvarez y Zoé Valdés realiza un estudio intercultural sobre dichas autoras en el contexto de la inmigración de origen caribeño. Leonor Sáez ofrece otro texto sobre el exilio de la Viena de entreguerras, en el capítulo 25, dedicado a Herminya Zur Mühlen. Finalmente, cierra el mosaico de escritoras del éxodo el estudio de Viviana Cinquemani, con una lectura según estas claves de Mare al mattino de Margaret Mazzantini, novela que denuncia la actual situación de los inmigrantes que desembarcan en las costas mediterráneas.

En conjunto, este libro representa una contribución muy valiosa para la crítica internacional sobre la obra de Marisa Madieri, así como para el estudio de otras trece escritoras de culturas distintas, cuya sensibilidad y talento han logrado testimoniar para la posteridad múltiples éxodos y exilios. Lamentablemente estas situaciones continúan hoy lacerando comunidades en todo el mundo; las mujeres demuestran a través de estos ejemplos, una extraordinaria capacidad para resistir y guardar las memorias de culturas minoritarias en riesgo. 